Volume 14, No 3 International Journal of Radiation Research, July 2016

\title{
Potent radioprotective effect of herbal immunomodulator drug (IMOD) on mouse bone marrow erythrocytes as assayed with the micronucleus test
}

\author{
A. Shakeri-Boroujeni', H. Mozdarani ${ }^{*}$, M. Mahmmoudzadeh3, \\ F. Faeghi ${ }^{1}$ \\ ${ }^{1}$ Department of Radiology Technology, Faculty of Paramedicine, Shahid Beheshti University of Medical Sciences, \\ Tehran, Iran \\ ${ }^{2}$ Department of Medical Genetics, Faculty of Medical Sciences, Tarbiat Modares University, Tehran, Iran \\ ${ }^{3}$ Novin Medical Radiation Institute, Tehran, Iran
}

\begin{abstract}
\section{- Original Article}

${ }^{*}$ Corresponding author:

Prof. Hossein Mozdarani,

Fax: +982188006544

E-mail:

mozdarah@modares.ac.ir

Revised: Feb. 2015

Accepted: June 2015

Int. J. Radiat. Res., July 2016;

14(3): 221-228

DOI: 10.18869 /acadpub.ijrr.14.3.221

Background: Although numerous natural or synthetic drugs have been tested for their radioprotective capacity, yet no suitable drug has been introduced for routine clinical use. In this study the radioprotective effect of "a new herbal immunomodulator" commercially known as IMOD, specifically made to decrease the side effects of HIV virus, was investigated on mouse bone marrow cells. Materials and Methods: Female NMRI mice (in a group of five) were exposed to $2 \mathrm{~Gy}$ gamma radiation following three days of intravenously injection (IV) of IMOD at various doses. Mice were sacrificed 48 and $72 \mathrm{~h}$ after irradiation. Bone marrow was flushed and slides for bone marrow smears were prepared according to standard method. After staining slides in May Grunwald and Giemsa, polychromatic erythrocytes (PCE) and normochromatic erythrocytes (NCE) were scored for presence of micronucleus (MN). Results: The results showed that gamma irradiation increased the frequency of micronuclei dramatically and excreted cytotoxic effect of cell proliferation. Injection of various doses of IMOD before irradiation however, led to a considerable reduction in the frequency of micronuclei in bone marrow erythrocytes as well as cellular toxicity. Conclusion: Results indicated radioprotective capability of IMOD with a dose reduction factor (DRF) of about 2.3 at a dose of $20 \mathrm{mg} / \mathrm{kg}$ body weight. The considerably high DRF might be indicative that IMOD besides being an immunomodulator might also posses' antioxidant property.
\end{abstract}

Keywords: Radioprotection, immunomodulator, IMOD, mouse bone marrow, micronucleus assay.

\section{INTRODUCTION}

Human is under constant exposure to ionizing radiation from natural sources and increasing use of ionizing radiation in modern life due to rapid technological advancement in industry and medicine. Moreover, radiation exposures to the living organisms could be accidental due to nuclear plants reactor accidents like Chernobyl or Fokoshima $(1,2)$ where a large population would be exposed to external or internal sources of ionizing radiation; or intended such as those used in diagnostic radiology or radiotherapy of cancer.

Ionizing radiations damage cells through direct or indirect action leading to various types of DNA damage. Although all radiation induced DNA damages are subjected to repair process, 
however unrepaired or inappropriately repaired DNA damages are the principal lesions in the induction of mutational events, chromosomal abnormality, apoptosis, cell death and cancer. Therefore there is a need to protect human from adverse effects of ionizing radiation (3). Physical shielding and other physical measures although useful in such situations but would be difficult to manage and in large scale nuclear or radiological accident it is impossible to use. Therefore, use of chemical radioprotectors to countermeasure deleterious effects of ionizing radiation has been proposed since 1949 by Patt and his co-workers (1949) who showed radioprotection of rats exposed to lethal doses of X-rays by amino-acid cysteine (4). Over the past 6 decades, a large number of aminothiols, naturally occurring products, immunomodelators and so on were investigated for their radioprotective potential. However, to date the only Food and Drug Administration (FDA) approved drug as a radioprotector for use in cancer patients is amifostine (WR2721) which emerged from a 4500 aminothiol compounds investigated at Walter Reed Army Research Institute (5). Although it is useful agent, but like many other aminothiols exerts some side effects like cephalalgia, nausea, sickness, vomiting, etc. (6) which necessitated search for alternative agents, with less toxicity, availability and orally administrable.

Amongst various types of compounds with rdioprotective potential, immunomodulators have attracted significant interest. Bone marrow stem cells have long been recognized as very sensitive tissue to ionizing radiation (7). In radiation accidents clinical expression of damage to bone marrow stem cells would be hematopoetic syndrome and in cancer patients' side effects of radiotherapy is suppression of immune system. Therefore, the strategy is to protect stem cells from indirect effects of radiation and also to increase survival rate by stimulating the function and regeneration of the stem cell population. Naturally occurring compounds that function as antioxidants such as vitamins E (8), C (9) and immunostimulants such as glucan (10), ginsan (11,12), 5-androstenediol or AED (13), famotidine and cimetidine (14-16) have proved protection of bone marrow stem cells from harmful effects of radiation. However, researches over past two decades indicate that plants are under extensive screening for their radioprotective potentials. Herbal products are preferable due to being nontoxic, inexpensive and harmless to human. Flavonoids and a range of herbs and plants based natural products are found to have radiation protection and anticancer properties (17-23).

In line with these studies, immunomodulator herbal drug that has been designed to reduce the side effects of human immunodeficiency virus (HIV) in Iran, called IMOD (IMmunOmodulator Drug) or Setarud was used to investigate its possible radioprotective capability. IMOD is prepared by ethanol herbal extract from Rosa canina, Urtica dioica, and Tanacetum vulgare, enriched with selenium and urea then exposed to a pulsed electromagnetic field (24). According to the nature of these primary ingredients, IMOD contain vitamin C, flavonoid, carotene and selenium. This compound (IMOD) have positive effect on immune system and have capacity to treat immune disordered (24). Previous studies showed that this compound increase the amount of cytokines such as Interleukin (IL) 4, IL12 and some immune element such as CD4, and reduce the level of tumor necrosis factor alpha (TNF- $\alpha$ ) and Interferon- $\gamma$ and IL-2 levels (25). Based on the existence of ingredients such as flavonoid, vitamin $\mathrm{C}$ and selenium in the formulation of this drug, its radical scavenging and antioxidative potential might be expected.

To evaluate radioprotective potential of IMOD, in vivo erythrocytes micronucleus assay was employed. Micronuclei are formed by acentric chromosomal fragments or lagging chromosomes visible as a small nucleus in the cytoplasm. The micronucleus test developed by Schmid and his colleagues in 1975 (26), is a reliable, sensitive and effective method for the evaluation of cytotoxic and clastogenic effects of physical and chemical agents in vivo (27). Therefore, the aim of this study was to investigate potential radioprotective property of IMOD on mouse bone marrow cells exposed to gamma radiation in terms of in vivo micronucleus assay. 


\section{MATERIALS AND METHODS}

\section{Animals}

Seven weeks old female NMRI mice were provided from University (Tehran, Iran) animal house. They were housed in cages for one week, provided with proper light, temperature and moisture, and fed with standard ration and water ad libitum. Eight-week old mice weighting $25 \pm 5 \mathrm{~g}$ were used for experiments. Animals were randomized equally into 20 groups of 5 animals per group. The study was approved by Ethical committee of Shahid Beheshti University of Medical Sciences and animals were treated according to the institutional guidelines.

\section{Drug Treatment}

Commercial intravenous (IV) ampoules of IMOD were kindly provided by the owner company of IMOD - Parsroos (Tehran, Iran). All ampoules were stored in a cold and dark place and checked for the expiration date. In each experiment, IMOD was used freshly after vial breakage. Various doses of IMOD $(5,10,15$ and $20 \mathrm{mg} / \mathrm{kg}$ body weight) were injected to the mice intravenously (IV) 3 days prior to 2 Gy gamma irradiation.

\section{Irradiation}

A 60-Co radiotherapy unit (Theratron II, 780 C, Canada) was used for gamma irradiation. The mice were grouped into 5 , kept in a plexi-glass box, and irradiated with 2 Gy gamma rays at room temperature $\left(25 \pm 1^{\circ} \mathrm{C}\right)$. The source to sample distance (SSD) was $85 \mathrm{~cm}$ and the dose rate was $94 \mathrm{cGy} / \mathrm{min}$. The mice were irradiated, some in the presence and some in the absence of different doses of IMOD.

\section{The micronucleus assay}

The mouse bone marrow micronucleus test was carried out according to the method described by Mozdarani and Gharbali (16). The irradiated mice in the presence or absence of IMOD as well as control groups were sacrificed by cervical dislocation 48 and 72 hours after irradiation. The femoral bone marrow of mice was flushed out by using fetal calf serum, and a cell suspension was prepared. The suspension was centrifuged for 7 minutes at $1000 \mathrm{rpm}$. After centrifuging, the supernatant was removed and cells were re-suspended in the remaining serum and a smear was prepared on clean glass slides. The slides were then fixed with methanol and stained in May Grunwald and Giemsa. In this method of staining, polychromatic erythrocytes (PCEs) are stained blue-violet, while normochromatic erythrocytes (NCEs) are stained yellow-orange (figure 1).

\section{Microscopic and statistical analysis}

A Nikon microscope (Y100, Japan) with $\times 100$ objective lens was used for scoring the cells. A total of 800-1000 PCEs and NCEs in the field was scored for the presence of micronuclei for each sample. In order to study the cytotoxic effects of gamma rays on the proliferation of the bone marrow cells, the ratio of PCEs/PCEs+NCEs was calculated. SPSS statistical software (version 18) was used for statistical analysis. The significance of any intergroup differences in the number of micronucleated PCEs, NCEs as well as the ratio of PCEs/PCEs+NCEs was statistically evaluated by the one-way analysis of variance (ANOVA) and Tukey's HSD test. $P$ value less than 0.05 was considered as significant. SPSS software (version 18) and Graph pad Prism (version 4) was used for data analysis and drawing figures.

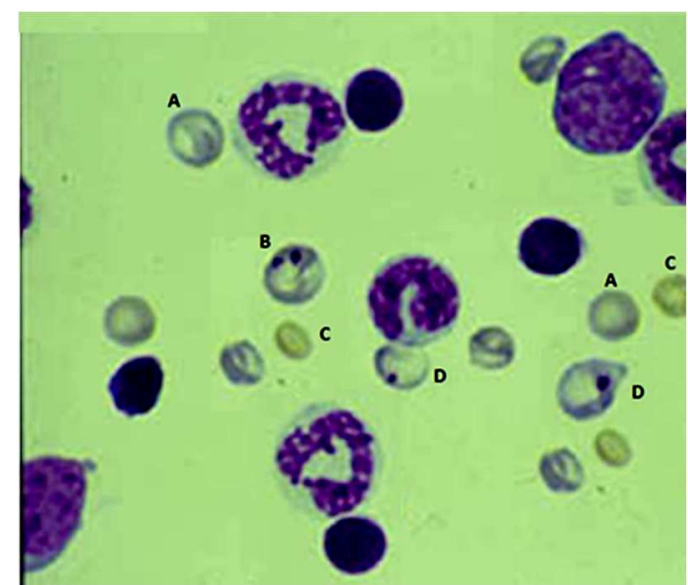

Figure 1. Photomicrograph of bone marrow cells on slides stained with May Grunwald and Giemsa showing polychromatic erythrocyte (PCE) (A), PCE with two micronuclei (B), normochromatic erythrocyte $(C)$ and PCE with one micronucleus (D). Magnification $\times 1000$

Int. J. Radiat. Res., Vol. 14 No. 3, July 2016 


\section{RESULTS}

The obtained results of the study are summarized in table 1 and shown in figure 2 . As shown in figure 2 and table 1 , whole body gamma irradiation of mice caused significant increase in the frequency of MNPCEs in comparison with the control group that is statistically different with $\mathrm{P}<0.001$. There was no significant difference in the frequency of radiation induced $\mathrm{MN}$ when sampling time increased from $48 \mathrm{~h}$ to $72 \mathrm{~h}$ post irradiation. Any doses of IMOD injected before irradiation reduced the frequency of MNPCEs to almost $50 \%$ comparing to those that had received only gamma irradiation $(\mathrm{p}<0.01)$. The effect was slightly dose dependent, although, dose of 20 $\mathrm{mg} / \mathrm{kg}$ IMOD was more effective in reducing the frequency of radiation induced $\mathrm{MN}$ both at 48 and $72 \mathrm{~h}$ sampling times compared to other doses used (table 1). Similar frequency of MN was observed for NCEs after irradiation alone or in combination with various doses of IMOD. No sampling time effect was seen for MNNCE too (table 1).

The statistical analysis performed for the cell proliferation ratio (PCEs/PCEs+NCEs) showed a significant difference between the control and gamma-irradiated groups $(\mathrm{p}<0.01)$. Also a significant difference was observed between the gamma irradiated group and each of the groups having received various doses of IMOD prior to irradiation (table 1) indicating restoration of bone marrow cell population by IMOD.

Table 2 illustrates the dose reduction factor (DRF) calculated for various doses of IMOD. DRF is calculated as the ratio of the frequency of MN induced by radiation to the frequency of radiation induced $\mathrm{MN}$ in the presence of various doses of IMOD.

Table 1. Summary of results obtained in the study. Data show mean frequency of micronuclei in PCEs and NCEs. At least 8001000 PCEs were analyzed for the presence of micronuclei. NCEs were scored in the field of PCEs. Errors are standard deviation of mean values obtained from five animals.

\begin{tabular}{|c|c|c|c|}
\hline Treatment & Mean \% MNPCE & Mean \% MNNCE & PCE/PCE+NCE \\
\hline Control & $2.8 \pm 0.09$ & $2.88 \pm 0.07$ & $50.2 \pm 1.23$ \\
\hline Alcohol (Ethanol) & $2.17 \pm 0.13$ & $2.45 \pm 029$ & $49.5 \pm 1.55$ \\
\hline IMOD $(5 \mathrm{mg} / \mathrm{kg}), 48 \mathrm{~h}$ & $2.95 \pm 0.16$ & $3.2 \pm 0.21$ & $49.1 \pm 0.17$ \\
\hline IMOD (10 mg/kg), $48 \mathrm{~h}$ & $2.82 \pm 0.14$ & $2.93 \pm 0.19$ & $49.26 \pm 0.04$ \\
\hline IMOD (15 mg/kg), $48 \mathrm{~h}$ & $2.81 \pm 0.11$ & $2.88 \pm 011$ & $49.17 \pm 1.22$ \\
\hline IMOD $(20 \mathrm{mg} / \mathrm{kg}), 48 \mathrm{~h}$ & $2.5 \pm 0.13$ & $2.7 \pm 0.15$ & $49.2 \pm 0.35$ \\
\hline Radiation, (2 Gy),48 h & $9.4 \pm 0.41$ & $7.4 \pm 0.34$ & $29.87 \pm 0.45$ \\
\hline $\operatorname{IMOD}(5 \mathrm{mg} / \mathrm{kg})+\mathrm{RAD}, 48 \mathrm{~h}$ & $5.61 \pm 0.20$ & $5.2 \pm 0.24$ & $41.2 \pm 0.63$ \\
\hline IMOD $(10 \mathrm{mg} / \mathrm{kg})+\mathrm{RAD}, 48 \mathrm{~h}$ & $4.65 \pm 0.15$ & $3.93 \pm 0.14$ & $42.4 \pm 0.72$ \\
\hline IMOD (15 mg/kg) + RAD, $48 \mathrm{~h}$ & $4.27 \pm 0.15$ & $3.83 \pm 0.12$ & $44.68 \pm 0.84$ \\
\hline IMOD $(20 \mathrm{mg} / \mathrm{kg})+\mathrm{RAD}, 48 \mathrm{~h}$ & $4.04 \pm 0.11$ & $3.25 \pm 0.15$ & $45.4 \pm 0.81$ \\
\hline IMOD (5 mg/kg), $72 \mathrm{~h}$ & $2.9 \pm 0.18$ & $3.2 \pm 0.18$ & $48.47 \pm 0.03$ \\
\hline IMOD (10 mg/kg), $72 \mathrm{~h}$ & $2.9 \pm 0.18$ & $3.09 \pm 0.11$ & $48.5 \pm 1.13$ \\
\hline IMOD (15 mg/kg), $72 \mathrm{~h}$ & $2.81 \pm 0.15$ & $2.88 \pm 0.18$ & $49.2 \pm 0.25$ \\
\hline IMOD (20 mg/kg), $72 \mathrm{~h}$ & $2.69 \pm 0.15$ & $2.85 \pm 0.16$ & $49.39 \pm 0.23$ \\
\hline Radiation (2 Gy), $72 \mathrm{~h}$ & $8.57 \pm 0.39$ & $9.06 \pm 0.43$ & $28.4 \pm 0.38$ \\
\hline IMOD $(5 \mathrm{mg} / \mathrm{kg})+\mathrm{RAD}, 72 \mathrm{~h}$ & $5.25 \pm 0.21$ & $5.37 \pm 0.15$ & $38.25 \pm 0.49$ \\
\hline IMOD (10 mg/kg) + RAD, $72 \mathrm{~h}$ & $4.27 \pm 0.17$ & $4.9 \pm 0.25$ & $40.6 \pm 0.57$ \\
\hline IMOD (15 mg/kg ) + RAD, $72 \mathrm{~h}$ & $4.07 \pm 0.19$ & $4.4 \pm 0.21$ & $41.1 \pm 0.51$ \\
\hline $\operatorname{IMOD}(20 \mathrm{mg} / \mathrm{kg})+\mathrm{RAD}, 72 \mathrm{~h}$ & $3.6 \pm 0.18$ & $3.7 \pm 0.12$ & $43.4 \pm 0.74$ \\
\hline
\end{tabular}




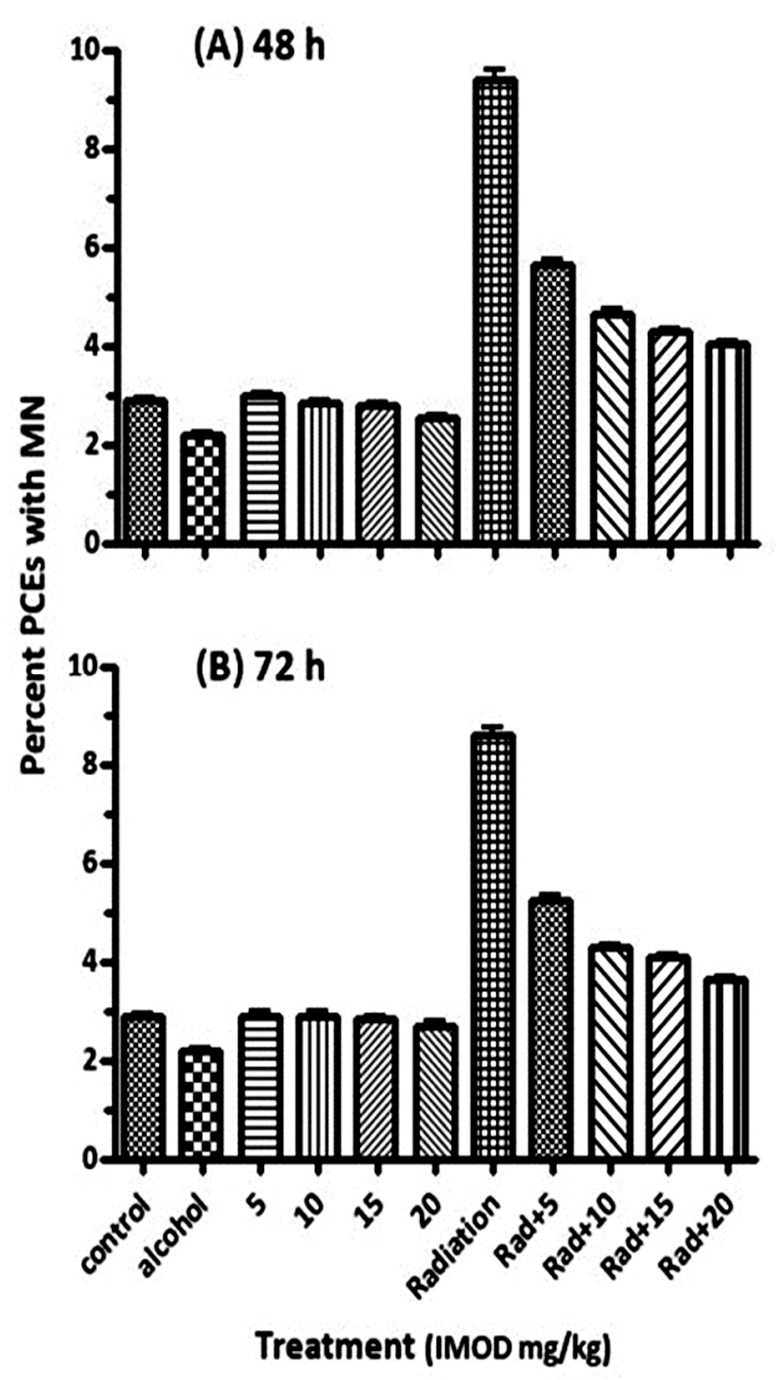

Figure 2. Comparison of results obtained for the frequency of micronuclei in PCEs after various treatments at different sampling times 48 (A) and 72 (B) hours. Error bars are indicating standard deviation of mean values obtained from 5 animals.

Table 2. Dose reduction factor (DRF) calculated for the effects of various doses of IMOD on radiation induced micronuclei in PCEs.

\begin{tabular}{|c|c|c|}
\hline IMOD (mg/kg) & Sampling time (h) & DRF \\
\hline 5 & 48 & 1.6 \\
\hline 10 & 48 & 2.01 \\
\hline 15 & 48 & 2.2 \\
\hline 20 & 48 & 2.32 \\
\hline 5 & 72 & 1.63 \\
\hline 10 & 72 & 2 \\
\hline 15 & 72 & 2.12 \\
\hline 20 & 72 & 2.38 \\
\hline
\end{tabular}

\section{DISCUSSION}

Radioprotective agents with different mode of actions; in particular, compounds with potential of regeneration of haematopoietic stem cells, have been under investigations during past years. The aim of this strategy is to stimulate the function and regeneration of the stem cells in bone marrow that is decreased or damaged by radiation and eventually to increase survival rate. The use of naturally occurring antioxidants and immunostimulants compounds has received particular attention for the development of radioprotective agents because of their low toxicity. Several plants based natural products have been explored for their radioprotective properties (19).

As shown in table 1, application of various doses of IMOD prior to 2 Gy gamma irradiation effectively reduced the frequency of micronucleus in PCEs. This reduction was not time dependent, i.e. relatively similar results was obtained for two different sampling times, 48 and 72 hours (figure 2). This reducing effect might be due to the presence of different ingredients such as flavonoid, vitamin $\mathrm{C}$ and selenium in the formulation of this herbal drug that are potent antioxidants.

Previous experiments have shown radioprotective effects of vitamin $C$ on various cellular systems and evaluation of different end points. Administration of vitamin $\mathrm{C}$ led to protection of lymphocytes against radiation induced apoptosis (28), rduction of transgenerational genetic effects in male germ cells (29), spermatogonia (30). Radioprotective potential of vitamin $\mathrm{C}$ on radiation induced micronucleus in mouse bone marrow erythrocytes was shown with a protection factor of 1.7 but when combined with famotidine a greater protection factor was observed (9). Similarly oral administration of vitamin $\mathrm{C}$ with other agents was shown to reduce the frequency of radiation induced micronuclei in bone marrow erythrocytes (31). Vitamin $\mathrm{C}$ has shown both radioprotective and mitigating effects when used before or after

Int. J. Radiat. Res., Vol. 14 No. 3, July 2016 
irradiation $(32,33)$. Therefore radioprotective potential observed for IMOD in this study might be partly due to presence of vitamin $\mathrm{C}$ in the formulation of this drug.

Because of their low toxicity, botanical and natural products have been evaluated for their radioprotective potentials. Plants containing polyphenolic compounds $(34,35)$, Naringenin (36), flavonoids of Rosa roxburghii Tratt (37), ocimum flavonoids $(38,39)$ have shown antioxidative activities and protect genetic material from ionizing radiation. Radioprotective effect of all tested herbal products were attributed to their antioxidant properties. Similarly selenium is also shown to have antioxidant activity (40-42). Therefore reduction of radiation induced micronuclei both in PCE and NCE by IMOD might be due to its antioxidant properties. As seen in table 2 dose reduction factor for various doses of IMOD show that the reducing effect was more than 2 above dose of $10 \mathrm{mg} / \mathrm{kg}$ body weight. This result is promising because indicate additive effects of antioxidants when used in combination. Therefore combination of different agents will eventually lead to radioprotective potential at much more low doses compared to each agent when used alone. Zangeneh et al. in a study using vitamin $\mathrm{C}$ and famotidine have shown combination of these two agents led to a greater DRF at lower doses (9). Similar observation was reported for oral administration of vitamin $\mathrm{C}$ in combination with cimetidine and famotidine (31).

There was significant difference in the ratio of PCE/PCE+NCE between control and radiation group. This result indicate that radiation can reduce the proliferation of bone marrow stem cells (table 1). However, presence of of IMOD before irradiation was able to reduce radiation induced cytotoxicity in bone marrow cells effectively. This effect was more pronounced at the dose of $20 \mathrm{mg} / \mathrm{kg}$ of IMOD (table 1). Reducing of cytotoxic effect of radiation in bone marrow cells might be due to increase in the amount of cytokines such as IL4, IL12 and some immune element such as CD4, and reduce the level of TNF- $\alpha$ and Interferon- $\gamma$ and IL-2 levels by IMOD (25). Therefore, IMOD not only is a potent anti-clastogenic but is also an

Int. J. Radiat. Res., Vol. 14 No. 3, July 2016 anti-cytotoxic agent against radiation induced clastogenic or cytotoxic effects. IMOD similar to other plant and natural products possesses qualities such as being non- or less toxic, relatively cheap, and could act through multiple mechanisms due to the presence of different chemicals and a reasonably good dose reduction factor. Therefore it could be a good candidate for radioprotection of bone marrow cells.

In conclusion, over the dose ranges used in this study $5-20 \mathrm{mg} / \mathrm{kg}$ bodyweight), IMOD was found a potent radioprotrector against radiation induced micronucleus in bone marrow erythrocytes. It also could effectively reduce cytotoxic effects and help regeneration and proliferation of bone marrow stem cells by its immunomodulatory potential.

\section{ACKNOWLEDGEMENTS}

The authors express their gratitude's and thanks to Prof. Shahram Akhlaghpoor director of Novin Medical Radiation Institute for his kind help and assistance in providing irradiation facilities and Prof. H.R Khorramkhorshid for providing IMOD. This work was supported in part by Iran National Science Foundation (INSF) under grant number 43800, Tehran, Iran.

\section{Conflict of interest: Declared none.}

\section{REFERENCES}

1. Ohnishi T (2012) The disaster at Japan's Fukushima-Daiichi nuclear power plant after the March 11, 2011 earthquake and tsunami, and the resulting spread of radioisotope contamination. Radiat Res, 177: 1-14.

2. Fushiki $S$ (2013) Radiation hazards in children-lessons from Chernobyl, Three Mile Island and Fukushima. Brain Dev, 35: 220-227.

3. Mozdarani H (2012) Biological Complexities in Radiation Carcinogenesis and Cancer Radiotherapy: Impact of New Biological Paradigms. Genes, 3: 90-114.

4. Patt HM, Tyree EB, Straube RL, Smith DE (1949) Cysteine protection against $X$ irradiation. Science, 110(2852): 213214.

5. Weiss JF and Landauer MR (2009) History and development of radiation-protective agents. Int $J$ Radiat 
Biol, 85: 539-573.

6. Kouvaris JR, Kouloulias VE, Vlahos LJ (2007) Amifostine: the first selective-target and broad-spectrum radioprotector. Oncologist, 12: 738-747.

7. Hall EJ and Giaccia AJ (2012) Radiobiology for the Radiobiologist. Philadelphia, PA: Lippincott Williams and Wilkins.

8. El-Nahas SM, Mattar FE, Mohamed AA (1993) Radioprotective effect of vitamins C and E. Mutat Res, 301: 143-7.

9. Zangeneh M, Mozdarani H, Mahmoudzadeh A (2015) Potent radioprotective effects of combined regimens of famotidine and vitamin $\mathrm{C}$ against radiation-induced micronuclei in mouse bone marrow erythrocytes. Radiat Environ Biophys, 54: 175-181.

10. Akramiene D, Kondrotas A, Didziapetriene J, Kevelaitis E (2007) Effects of beta-glucan on the immune system. Medicina (Kaunas), 43(8): 597-606.

11. Kim HJ, Kim MH, Byon YY (2007) Radioprotective effects of an acidic polysaccharide of panax ginseng on bone marrow cells. J Vet Sci, 8: 39-44.

12. Lee Tk, Johnke RM, Allison RR, Kevin F, Brien O, Dobbs LJ (2005) Radioprotective potential of ginseng. Mutagenesis, 20(4): 237-243.

13. Stickney DR, Dowding C, Authier S (2007) 5-androstenediol improves survival in clinically unsupported rhesus monkeys with radiation-induced myelosuppression. Int J Immunopharmacol, 7: 500-505.

14. Mozdarani H, Salimi M, Froughizadeh M (2008) Effect of cimetidine and famotidine on survival of lethally gamma irradiated mice Iran. J Radiat Res, 5(4): 187-19.

15. Shahidi M and Mozdarani H (2003) Potent radioprotective effect of therapeutic dosesofranitidine and famotidine against gamma-rays induced micronuclei in vivo. Iran J Radiat Res, 1(1): 29 - 35.

16. Mozdarani H and Gharbali A (1993) Radioprotective effects of Cimetidine in mousebone marrow cells exposed to gamma rays as assayed by the micronucleus test. Int $J$ Radiat Biol, 64: 189-194.

17. Adhvaryu MR, Srivastav SP, Vaniawala S, Reddy MN (2008) A comparative study of radioprotection by four Indian medicinal herbs against genotoxicity induced by sub-lethal gamma irradiation in Swiss albino mice. Iran J Radiat Res, 6(1): 19-30.

18. Paul P, Unnikrishnan MK, Nagappa AN (2011) Phytochemicals as radioprotectors. Indian Journal of Natural Products and Resources, 2(2): 137-150.

19. Shastry CS, Aswathanarayana BJ, Ganesh S, Kalluraya B, Santanu S, Atanu B (2012) Herbal radioprotector: reemerging trend in the field of radio therapy. Journal of Pharmacy Research, 5(4): 2355-2365

20. Nair CKK and Menon A (2013) Consumption of antioxidant dietary agents, curcumin and vitamin C, protects cellular DNA from gamma-radiation. Int J Radiat Res, 11(1): 11-16.

21. Bala K, Saini P, Katare DP (2014) Current status and future potential of herbal radioprotectants. World Journal of Pharmacy and Pharmaceutical Sciences, 3(8): 1341-1366.
22. Li Y-N, Zhang W-B, Zhang J-H, Xu P, Hao M-H (2016) Radioprotective effect and other biological benefits associated with flavonoids. Tropical Journal of Pharmaceutical Research, 15(5): 1099-1108.

23. Painuli $S$ and Kumar N (2016) Prospects in the development of natural radioprotective therapeutics with anti-cancer properties from the plants of Uttarakhand region of India. Journal of Ayurveda and Integrative Medicine, 7: 62-68.

24. Khorramkhorshid HR, Novitsky A, Abdollahi $Y$, Shahhosseiny M, Sadeghi B, Madani H, Rahimi R, Farzamfar B (2008) Studies on potential mutagenic and genotoxic activity of Setarud. DARU, 16(4): 223-228.

25. Khoramkhorshid HR, Moshfegh A, Mahdavi B, VeladimirBakayev V, Shahhoseini MH, Gharibdust F (2007) Evaluation of IMOD influence on cytokine profile in skin blister exudates healthy subject. Iran J Allergy, Asthma Immunol, 6: s11-s22.

26. Schmid W (1975) The Micronucleus Test. Mutat Res, 31: 915.

27. Mozdarani H (2003) Radioprotective properties of histamine $\mathrm{H} 2$ receptor antagonists: Present and future prospects. J Radiat Res, 44: 145-149.

28. Mozdarani H, Ghoraeian P (2008) Modulation of gammaray-induced apoptosis in human peripheral blood leukocytes by famotidine and vitamin C. Mutat Res, Genet Toxicol Environ Mutage, 649: 71-78.

29. Mozdarani $\mathrm{H}$ and Nazari E (2009) Cytogenetic damages in preimplantation mouse embryos generated after paternal and parental gamma-irradiation and the influence of vitamin C. Reproduction, 137(1): 35-43.

30. Mahdavi M and Mozdarani H (2011) Protective effects of famotidine and vitamin $\mathrm{C}$ against radiation induced cellular damage in mouse spermatogenesis process. Int $\mathrm{J}$ Radiat Res, 8(4): 223-230.

31. Naeeji A, Mozdarani H, Shabestani Monfared A, Faeghi F, Ahmadi AA, Gholami M, Behzadi R, Momtaz MR (2016) Oral Administration of Vitamin C, Cimetidine and Famotidine on Micronuclei Induced by Low Dose Radiation in Mouse Bone Marrow Cells. J Biomed Phys Eng, accepted in press.

32. Citrin D, Cotrim AP, _Hyodo F, Baum BJ, Krishna MC, Mitchell JB (2010) Radioprotectors and Mitigators of Radiation-Induced Normal Tissue Injury. The Oncologist, 15 (4): 360-371.

33. Mortazavi S, Foadi M, Mozdarani H, Haghani M, MoslehShirazi M, Abolghasemi $P$, et al. (2015) Future role of vitamin $C$ in radiation mitigation and its possible applications in manned deep space missions: survival study and the measurement of cell viability . Int J Radiat Res, 13 (1): 55-60.

34. Kuntic VS, Stankovic MB, Vujic ZB, Brboric JS, UskokovicMarkovic SM. (2013) Radioprotectors; the evergreen topic. Chem Biodivers, 10: 1791e803.

35. Li Y-N, Zhang W-B, Zhang J-H, Xu P, Hao M-H (2016) Radioprotective effect and other biological benefits associated with flavonoids. Trop J Pharm Res, 15(5): 1099- 
1108.

36. Kumar S and Tiku AB (2016) Biochemical and Molecular Mechanisms of Radioprotective Effects of Naringenin, a Phytochemical from Citrus Fruits. J Agric Food Chem, 64 (8): 1676-1685.

37. Xu P, Zhang WB, Cai XH, Lu DD, He XY, Qiu PY, Wu J (2014) Flavonoids of Rosa roxburghii Tratt act as radioprotectors. Asian Pacific J Cancer Preven, 15(19): 8171-8175.

38. Reshma K, Ashalatha VR, Dinesh M, Vasudevan D (2005) Effect of ocimum flavonoids as a radioprotector on the erythrocyte antioxidants in oral cancer. Indian J Clin Biochem, 20(1): 160-4.

39. Reshma K, Rao AV, Dinesh M, Vasudevan DM (2008) Radioprotective effects of ocimum flavonoids on leukocyte oxidants and antioxidants in oral cancer. Indian J Clin Biochem, 23(2): 171-175.

40. Londhe JS, Devasagayam TP, Foo LY, Ghaskadbi SS (2009) Radioprotective properties of polyphenols from Phyllanthus amarus Linn. J Radiat Res, 50: 303-9.

41. Veerapur VP, Prabhakar KR, Parihar VK, Kandadi MR, Ramakrishana S, Mishra B, et al. (2009) Ficus racemosa Stem Bark Extract: A Potent Antioxidant and a Probable Natural Radioprotector. Evid Based Complement Alternat Med, 6: 317-24.

42. Benkovic V, Knezevic AH, Dikic D, Lisicic D, Orsolic N, Basic I, et al. (2009) Radioprotective effects of quercetin and ethanolic extract of propolis in gamma-irradiated mice. Arh Hig Rada Toksikol, 60: 129-38. 